\title{
Millennial to centennial changes in deep- ocean ventilation during the last deglaciation
}

\author{
Tianyu Chen ${ }^{1}$ and Laura F. Robinson ${ }^{2}$
}

\begin{abstract}
The history of ocean ventilation helps to resolve timing and pathways of carbon transfer between the ocean and the atmosphere. Radiocarbon records reveal climate-linked, abrupt changes in the deep-ocean ventilation during the last deglaciation.
\end{abstract}

\begin{abstract}
Radiocarbon as an ocean-ventilation proxy The transport of surface seawater to depths, known as "ventilation", represents a fundamental aspect of our climate system as it is tightly linked to the dynamics of overturning circulation and the global carbon cycle. Proxy-based reconstruction of past ventilation makes it possible to examine the interaction between the ocean and the atmosphere on long timescales when instrument records are not available. Among various proxies, ${ }^{14} \mathrm{C}$ is one of the most sensitive for characterizing past deep-ocean ventilation. In the ocean interior, ${ }^{14} \mathrm{C}$ is exclusively supplied through ventilation of the ocean from surface to deep, and it decays away with a half-life of 5730 years. Today, a large portion of ${ }^{14} \mathrm{C}$ in the abyssal ocean (Fig. 1) is derived from the formation of North Atlantic Deep Water (NADW), with less than a third from overturning circulation in the Southern Ocean and biological remineralization (Broecker and Peng 1982). Since there is little deep convection in the present North Pacific, it contains the least ventilated waters at $\sim 2 \mathrm{~km}$ depth (where the ventilation age is defined as the ${ }^{14} \mathrm{C}$ age difference between the sample and the contemporaneous atmosphere) resulting from the slow transit of bottom water from the Southern Hemisphere. Along with the ${ }^{14} \mathrm{C}$-aging of the deep-water masses, there is a concomitant increase in the dissolved inorganic carbon inventory $(\sim 0.14 \mu \mathrm{mol} / \mathrm{kg} / \mathrm{year}$; Fig. 1) associated with the organic carbon respiration and calcite dissolution. As such, ${ }^{14} \mathrm{C}$ is widely used as a semi-quantitative chronometer of ocean ventilation providing critical constraints on circulation dynamics and carbon storage in the past.
\end{abstract}

The reconstruction of past deep-water ${ }^{14} \mathrm{C}$ signatures is not straightforward, as an independent age is required to correct for in-situ ${ }^{14} \mathrm{C}$ decay in paleoarchives since their formation. Most deep-ocean radiocarbon records have been reconstructed using the fossilized remains of benthic foraminifera extracted from sediment cores (e.g. Skinner et al. 2010). Deep-sea scleractinian corals form a complementary emerging new archive that provides well-constrained, absolute-dated ${ }^{14} \mathrm{C}$ records of the sub-surface ocean (e.g. Frank et al. 2004; Burke and Robinson 2012; Chen et al. 2015; Hines et al. 2015) since the Last Glacial Maximum (LGM).
Millennial-scale changes in ventilation The low atmosphere $\mathrm{CO}_{2}$ concentration during the LGM is thought to be largely caused by coupled oceanic changes in ventilation and the biological pump. Indeed, compiled radiocarbon data suggest an $\sim 700$ ${ }^{14} \mathrm{C}$-year increase in the average residence time of carbon in the deep ocean (>1 km) during the LGM compared to the modern ocean, which allows the ocean to store more carbon (Skinner et al. 2017). So how did the deep ocean switch from an isolated, poorly ventilated LGM mode to the opposite in the Holocene? The key lies in the timing and pathways of the dissipation of ${ }^{14} \mathrm{C}$-depleted signatures of the deep ocean during the last deglaciation.

During the early deglaciation when the Northern Hemisphere was experiencing a cold stadial (Heinrich Stadial 1, HS1), the atmospheric $\mathrm{CO}_{2}$ concentration was increasing accompanied by a $\triangle^{14} \mathrm{C}$ decrease (Fig. 2; Reimer et al. 2013), implying mixing from a ${ }^{14} \mathrm{C}$-depleted $\mathrm{CO}_{2}$ source. Radiocarbon data from the upper and lower circumpolar deep waters (UCDW and LCDW) highlight converging trends in ventilation ages, indicative of increased Southern Ocean deep convection and air-sea exchange efficiency. This would have brought well-ventilated waters to depths and released ${ }^{14} \mathrm{C}$-depleted $\mathrm{CO}_{2}$ to the atmosphere (Anderson et al. 2009; Skinner et al. 2010; Burke and Robinson 2012; Chen et al. 2015).

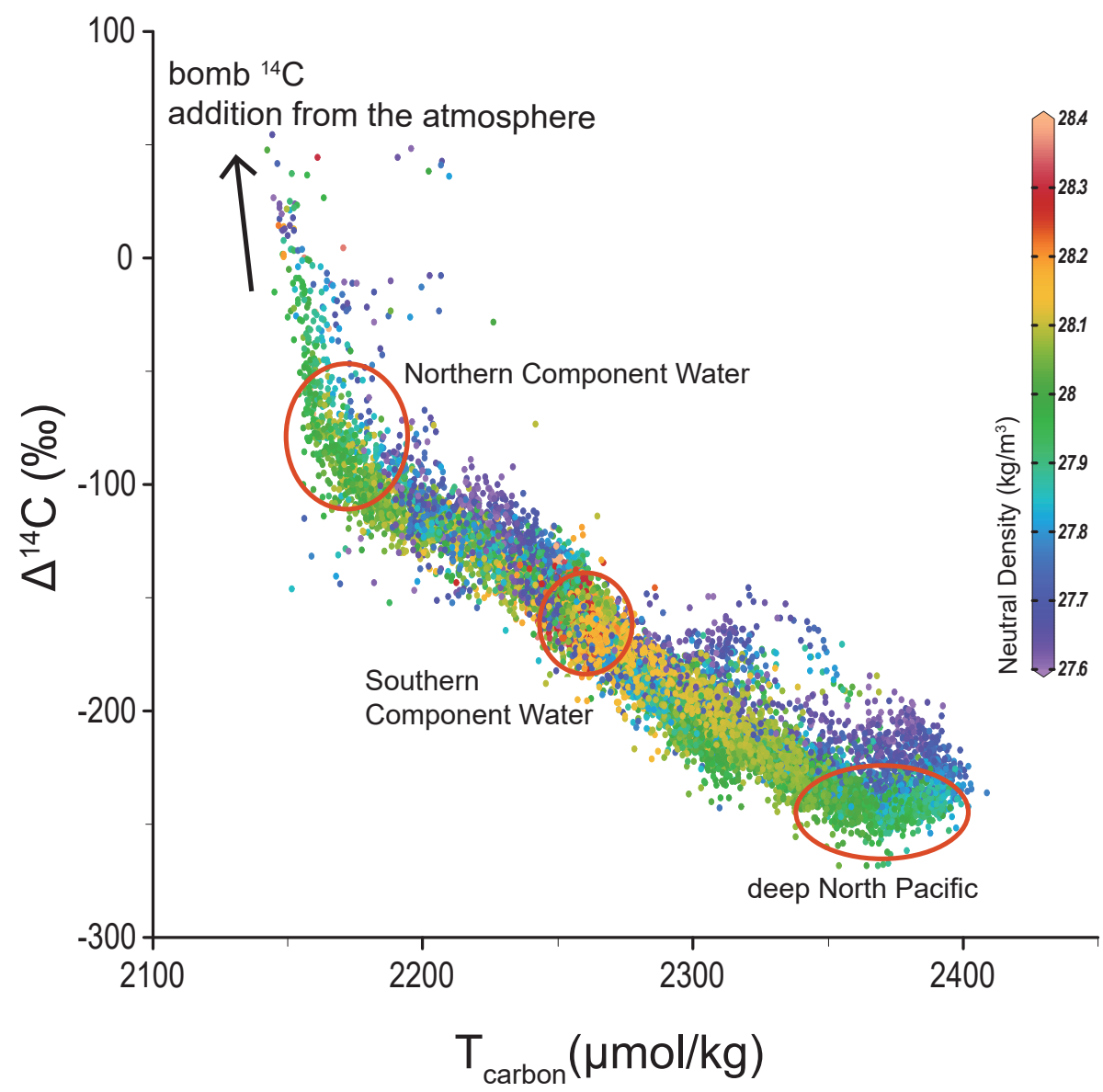

Figure 1: Modern distribution of $\triangle^{14} \mathrm{C}$ and total carbon in deep waters of the global ocean (defined as those with neutral density $>27.6 \mathrm{~kg} / \mathrm{m}^{3}$ ). Note that nuclear bomb testing since the 1950 s has dramatically increased the level of ${ }^{14} \mathrm{C}$ in the atmosphere and subsequently deep waters in the North Atlantic. Figure was made with Ocean Data View, and the data are from GLODAP 2019. 


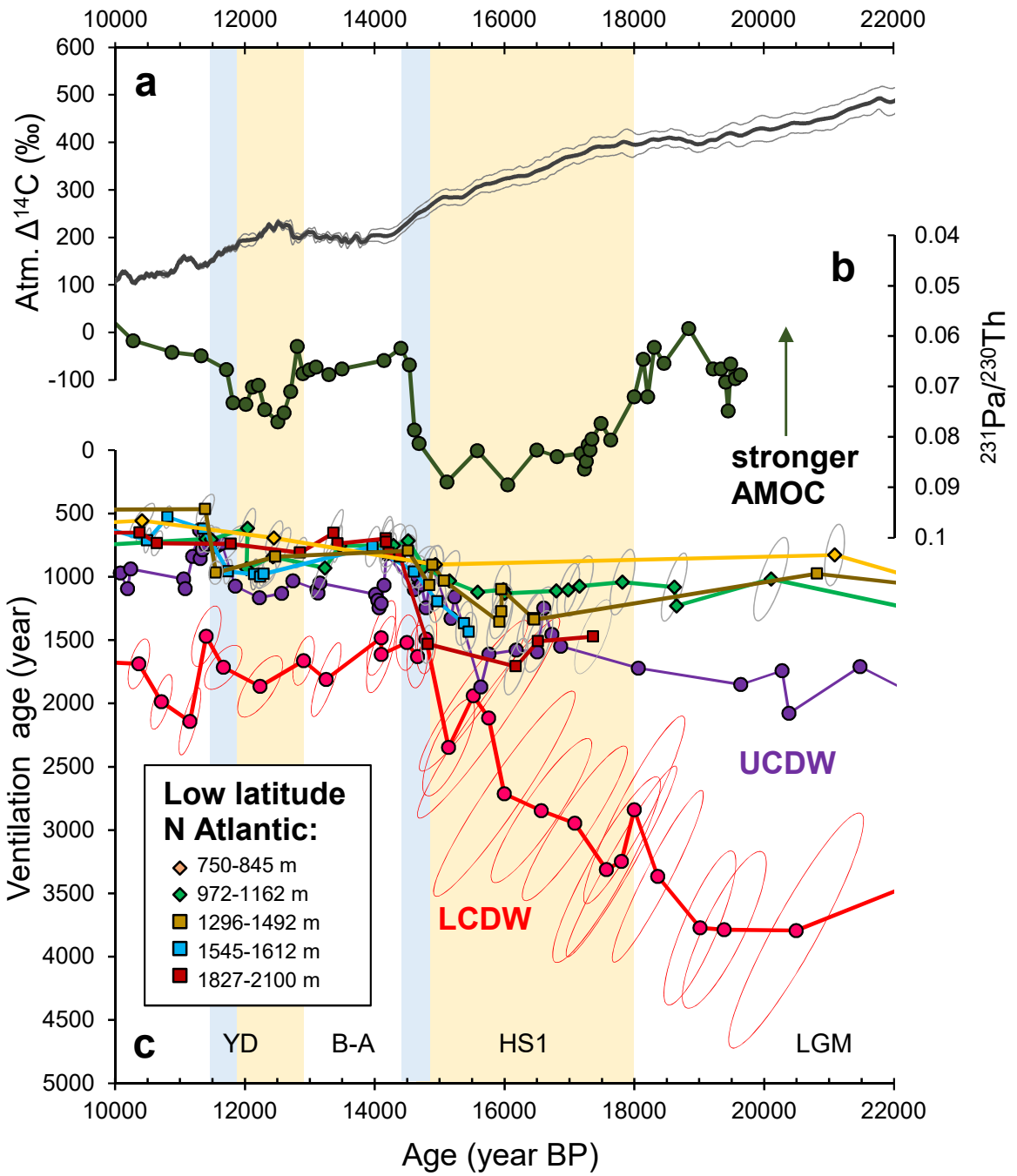

Figure 2: Ventilation age evolution of deep waters compared with other climate records. (A) $\Delta^{14} \mathrm{C}$ of the atmosphere (IntCal13, Reimer et al. 2013). (B) Sedimentary ${ }^{231} \mathrm{~Pa} /{ }^{230} \mathrm{Th}$ ratios (an AMOC-strength index) from the subtropical North Atlantic (McManus et al. 2004). (C) Ventilation age reconstructed from deep-sea corals (UCDW and low latitude Atlantic; Burke and Robinson 2012; Chen et al. 2015) and benthic foraminifera (LCDW: Skinner et al. 2010).

Meanwhile, low-latitude North Atlantic deep waters at $\sim 2 \mathrm{~km}$ remained poorly ventilated throughout HS1, some $700-800$ years "older" than modern times (Fig. 2). This result is consistent with greatly reduced Atlantic Meridional Overturning Circulation (AMOC) during HS1 (McManus et al. 2004) that reduced the supply of ${ }^{14} \mathrm{C}$-enriched waters to the deep North Atlantic. In fact, the deep North Atlantic might have accumulated carbon during HS1 due to reduced ventilation (Menviel et al. 2018). Similar processes probably occurred during the Younger Dryas (YD) albeit with a smaller magnitude. Overall, larger ${ }^{14} \mathrm{C}$ depth gradients are observed in the low-latitude North Atlantic during cold HS1 and YD compared to the Bølling-Allerød (B-A) warm event (Fig. 2), closely linked with changing production of the well-ventilated North Atlantic deep waters (McManus et al. 2004).

\section{Centennial abrupt changes in ventilation}

A particularly exciting aspect of the data being collected from deep-sea corals is the potential to reveal oceanic changes that occurred on centennial timescales. The transitions from HS1 to the B-A and from the
YD to the Holocene are marked by abrupt increases in ${ }^{14} \mathrm{C}$ of the low-latitude North Atlantic waters (Fig. 2), synchronous with warmings recorded in the Greenland ice cores and rapid increases in atmospheric $\mathrm{CO}_{2}$ concentrations (Chen et al. 2015). The coral ${ }^{14} \mathrm{C}$ records from the Atlantic and the Southern Oceans also converge during these two transitions. This convergence likely reflects "flushing" events resulting from the abrupt resumption of the AMOC which released a large amount of respired carbon from the deep ocean to the atmosphere (Chen et al. 2015).

At the same time, boron-based $\mathrm{pH}$ reconstructions from Southern Ocean deepsea corals further imply that these strong centennial ventilation events might be associated with delayed sea-ice advances at the beginning of the interstadial, allowing more efficient air-sea exchange (Rae et al. 2018). Multiple causes have to be invoked to account for the carbon release at the end of HS1 and the YD. Atmospheric $\delta^{13} \mathrm{C}$ records, for example, do not show the change expected from release of respired $\mathrm{CO}_{2}$ during the above two intervals, indicating increasing SST and/or increased land biosphere could also have played a role (Bauska et al. 2016). Moreover, the increased supply of nutrients to the surface is expected to stimulate primary productivity, enhancing the loss of alkalinity from surface waters and facilitating carbon release by increased overturning (Bronselaer et al. 2016). These puzzles are being addressed through increasing the resolution of data at these and other important oceanographic locations.

\section{Concluding remarks}

The upwelled ${ }^{14} \mathrm{C}$-depleted signatures from the abyssal ocean should eventually dissipate in the upper ocean and the atmosphere. Many uncertainties, unfortunately, still remain regarding intermediate water ventilation, with some ${ }^{14} \mathrm{C}$ reconstructions closely tracking the evolution of atmospheric ${ }^{14} \mathrm{C}$ while others showed extreme ${ }^{14} \mathrm{C}$ depletions. Some studies further suggest that geological carbon addition to the water column could be an important component of the deglacial carbon cycle (e.g. Stott et al. 2019). In addition, consensus has not been reached regarding the magnitude and timing of ${ }^{14} \mathrm{C}$ variability in the deep Pacific during the last deglaciation. Thus, the timing and pathways of deglacial oceanic carbon release have not yet been fully resolved. A growing understanding of ${ }^{14} \mathrm{C}$ geochemistry in foraminifera and emerging deep-sea coral studies from the Pacific will provide a fresh look at these issues. Overall, ${ }^{14} \mathrm{C}$ reconstructions of the deep ocean yield powerful constraints on ocean dynamics and carbon cycle during the last deglaciation.

\section{AFFILIATIONS}

'School of Earth Sciences and Engineering, Nanjing University, China

${ }^{2}$ School of Earth Sciences, University of Bristol, UK

\section{CONTACT}

Tianyu Chen: tianyuchen@nju.edu.cn

\section{REFERENCES}

Anderson RF et al. (2009) Science 323: 1443-1448 Bauska TK et al. (2016) Proc Natl Acad Sci 113: 3465-3470 Broecker W, Peng T (1982) Tracers in the sea, Palisades, New York: 690 pp

Bronselaer B et al. (2016) Global Biogeochem Cy 30 : 844-858

Burke A, Robinson LF (2012) Science 335: 557-561 Chen T et al. (2015) Science 349: 1537-1541 Frank N et al. (2004) Earth Planet Sc Lett 219: 297-309 Hines SK et al. (2015) Earth Planet Sc Lett 432: 46-58 McManus JF et al. (2004) Nature 428: 834-837 Menviel L et al. (2018) Nat Commun 9: 2503 Rae JWB et al. (2018) Nature 562: 569-573 Reimer PJ et al. (2013) Radiocarbon 55: 1869-1887 Skinner LC et al. (2010) Science 328: 1147-1151 Skinner LC et al. (2017) Nat Commun 8: 16010 Stott LD et al. (2019) Environ Res Lett 14: 025007 